\title{
AN ADVANCED CAST/WROUGHT TECHNOLOGY FOR GH720LI ALLOY DISK FROM FINE GRAIN INGOT
}

\author{
Yuxin Zhao, Shuhong Fu, Shaowei Zhang, Xin Tang, Na Liu, Guoqing Zhang \\ National Key Laboratory of Science and Technology \\ on Advanced High Temperature Structural Materials \\ Beijing Institute of Aeronautical Materials, Beijing 100095, China
}

Keywords: Fine grain; Cast \& wrought; Highly alloyed superalloy; GH720Li

\begin{abstract}
The cast $\&$ wrought $(\mathrm{C} \& \mathrm{~W})$ route is one of the earliest production techniques and still commonly used in the overall production of turbine components due to its low cost and processing benefits. However, the $\mathrm{C} \& \mathrm{~W}$ route can not be applied to some modern disk alloys that contain high volume fraction of $\gamma^{\prime}$ phase and refractory alloying elements. Therefore, the latest Ni-base disk alloys such as RR1000, Rene 95 and ME3 are produced by powder metallurgy processing routes. However, the requirement of clean powder and subsequent thermo-mechanical processing steps economically limit its applications in some cases.

Recent development in fine grain ingot casting technology is demonstrated in this investigation. The experimental results indicate that it is possible to convert highly alloyed GH720Li alloy directly from fine grain ingot to billet without powder process. The experimental fine grain ingot is sound and crack-free, typically with an uniform grain size ASTM 1 3. Hot ductility of the fine grain ingot has been systematically studied by hot compression testing, optical microscopy and scanning electron microscopy. Based on these results, a hot die forged pancake was produced with an ASTM 7 fine grain structure, which demonstrates the potential of GH720Li alloy disk to meet the component technical requirement.
\end{abstract}

\section{Introduction}

The latest design of large high thrust aero-engines lead to ever increasing demands on materials with higher mechanical properties and temperature capability, especially for the materials used for disks [1, 2]. Traditional alloys such as Inconel 718 and Waspaloy become less viable materials. To meet the more demanding requirements, highly alloyed, high strength superalloys are required. By increasing the volume fraction of $\gamma^{\prime}$ phase and adding strong solid solution hardening elements (W and Mo), the disk alloys such as RR1000, Rene 95 and ME3 were developed. However, such an increase in $\gamma^{\prime}$ phase volume fraction, combined with increased refractory elements contents, make it difficult to process these alloys by the conventional vacuum induction melting plus vacuum arc remelting (VIM/VAR) ingot and traditional forging sequences used for Inconel 718 and Waspaloy because of segregation and cracking problems. Therefore, these alloys are produced by powder metallurgy technology. Generally speaking, powder metallurgy needs ultra clean powder as source material and its thermomechanical process is complicated and expensive, which economically limit its applications. 
Alloy $720 \mathrm{Li}$ is a typical highly alloyed superalloy, which was originally designed for cast and wrought $(\mathrm{C} \& \mathrm{~W})$ land based gas turbine blades [3]. Alloy $720 \mathrm{Li}$ was also adopted for other applications such as turbine disks. It has been extensively used as turbine disk for aero-engines such as T800, T406, MA2100 and GMA3077 in C\&W form [4, 5]. Alloy 720Li alloy powder is converted to billet disk production by hot extrusion and isothermal forging [6, 7]. However, large extrusion facilities are currently not available in China. Recent development of fine grain ingot casting technology makes it possible to process highly alloyed superalloy without powder metallurgy technology. The key procedures for this advanced $\mathrm{C} \& \mathrm{~W}$ technology are as follows: (1) production of fine grain ingot, and (2) processing methods capable of converting the ingot into billet mainly including homogenization treatment and forging. This paper describes the development and optimization of processing methods from fine grain ingot.

\section{Experimental Procedure}

GH720Li is a high strength nickel-base superalloy. Its composition for this investigation is given in Table I. Several fine grain ingots have been produced by means of advanced casting methods, which involve controlling the superheat practices, mold heat extraction system and controlled dendrite growth process.

Cylindrical samples with a diameter $10 \mathrm{~mm}$ and a height of $15 \mathrm{~mm}$ for Gleeble testing were machined from $1 / 2$ diameter along the axial orientation of a fine grain ingot. Isothermal compression tests were conducted on Gleeble 1500 at temperatures $1110^{\circ} \mathrm{C} \sim 1150^{\circ} \mathrm{C}$, with strain rates of $0.001 \mathrm{~s}^{-1} \sim 0.1 \mathrm{~s}^{-1}$ and engineering strain of $40 \% \sim 70 \%$. Prior to compression, each specimen was soaked at the test temperature for $10 \mathrm{~min}$ to obtain temperature uniformity. Load and stroke data from the tests were acquired by computer and later converted to true-stress strain curves. After the compression test, the specimens were air cooled. The deformed samples were sectioned through the longitudinal axis and metallographically prepared. The microstructure was examined by utilizing a Leica optical microscope and JEOL scanning electron microscope (JSM-5600LV).

Table I Chemical composition of GH720Li by weight \%

\begin{tabular}{|c|c|c|c|c|c|c|c|c|c|c|}
\hline Alloy & C & B & Cr & Co & Mo & W & Ti & Al & Zr+Ce & Ni \\
\hline GH720Li & 0.02 & 0.02 & 16.3 & 14.32 & 2.93 & 1.18 & 4.88 & 2.4 & Trace & Bal. \\
\hline
\end{tabular}

\section{Experimental Results}

\section{Fine Grain Ingot Casting Technology}

The experimental results indicate that the fine grain casting technique is capable of producing sound, crack-free fine grain ingot with an ASTM 1-3 grain size (Figure1a). Its microstructure exhibits eutectic $\gamma+\gamma^{\prime}$ phases either at interdendritic or intergranular locations (Figure1b and c). Energy dispersive spectroscopy (EDS) results in conjunction with scanning electron microscopy (SEM) indicate that the most heavily segregated alloying elements are $\mathrm{Ti}$ and $\mathrm{W}$ with a segregation coefficient of 2.59 and 4.04, respectively. Therefore a homogenization treatment is necessary before processing to minimize cracking during forging. 

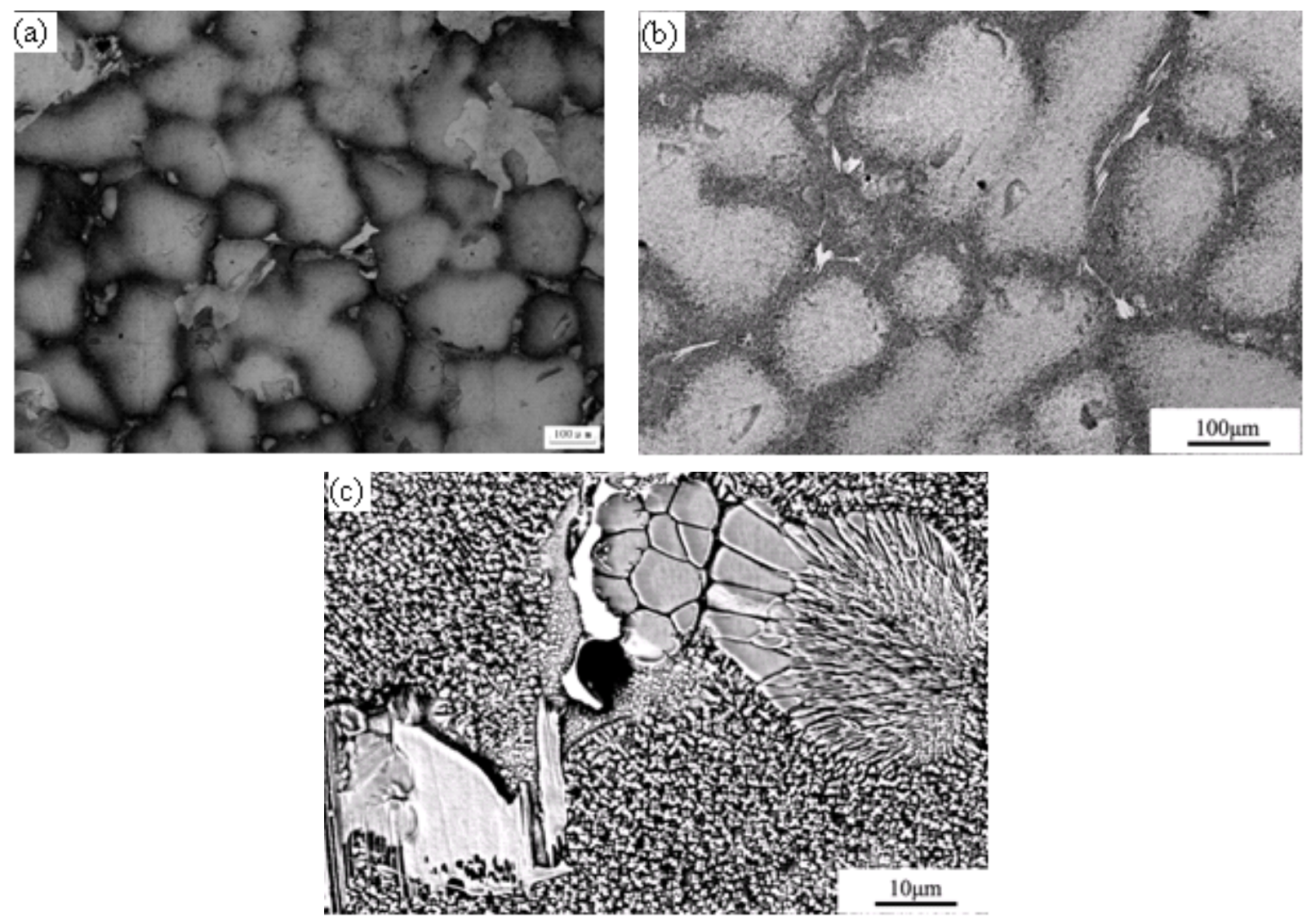

Figure 1 Grain size (a) and microstructure (b)(c) of fine grain ingot GH720Li alloy at as-cast condition

\section{$\underline{\text { Forging Process Development }}$}

(1) Original Forging Approach

Isothermal compression of as-cast condition samples at $1110^{\circ} \mathrm{C} \sim 1150^{\circ} \mathrm{C}$ with strain rates $0.001 \mathrm{~s}^{-}$

${ }^{1} \sim 0.1 \mathrm{~s}^{-1}$ results in significant cracking even at low reductions $(40 \%)$. In order to improve the forgeability of fine grain ingot, one stage and two stage thermal treatments were conducted before isothermal compression. The temperature was carefully selected according to $\gamma^{\prime}$ solvus so as to prevent grain growth. Figure 2 show the grain structure after one stage and two stage thermal treatment, which indicate that most of eutectic $\gamma+\gamma^{\prime}$ phases either at interdendritic or intergranular locations are all dissolved into solid solution and the grain growth is not evident when compared with the cast condition (Figure1 a).

After thermal treatment, a series of compression trials were conducted to assess flow stress, material recrystallization and surface cracking. Figure 3 shows the sample surfaces after compression test. The effect of deformation parameters on recrystallization is shown in Figure 4. Based on these experimental results, the preferred forge process sequence consisted of one stage or two stage thermal treatment and combination of forge parameters of $1130^{\circ} \mathrm{C}, 0.1 \mathrm{~s}^{-1}$ with the forging reduction limited to $50 \%$ to minimize cracking. 

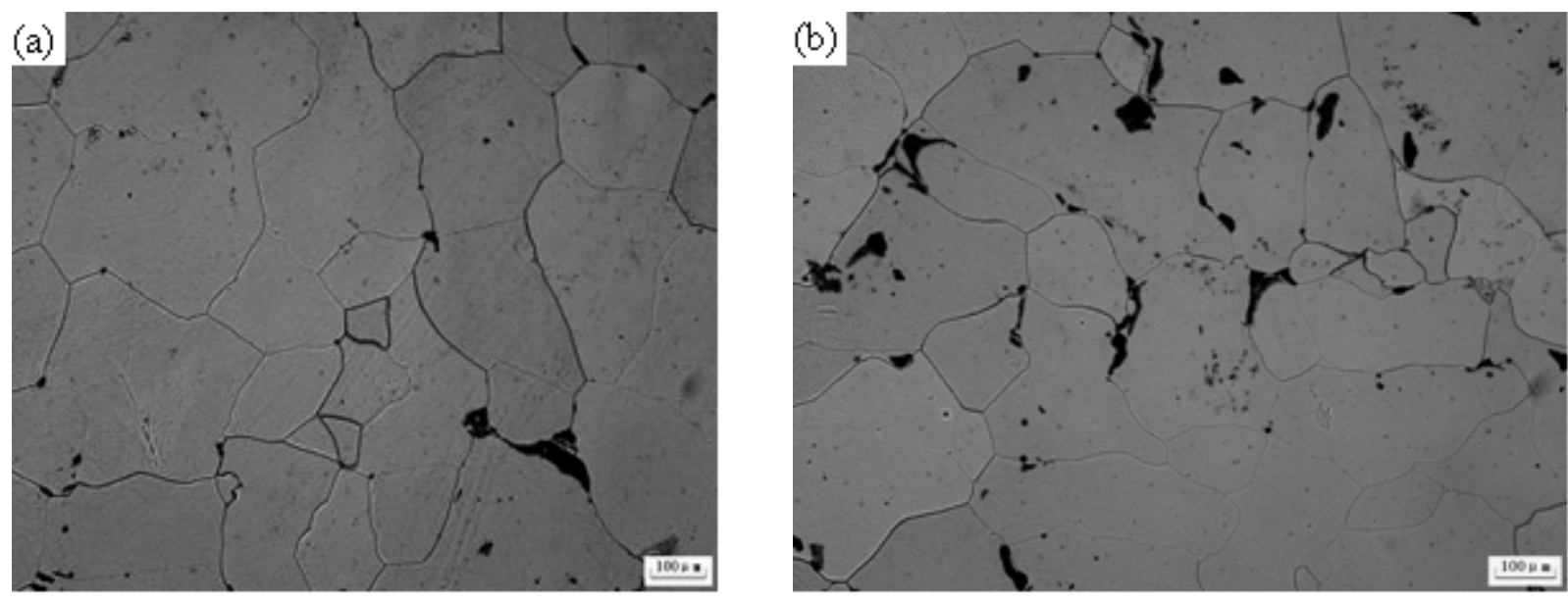

Figure 2 Grain structure of the fine grain ingot after

(a) one stage (b) two stage homogenization treatment

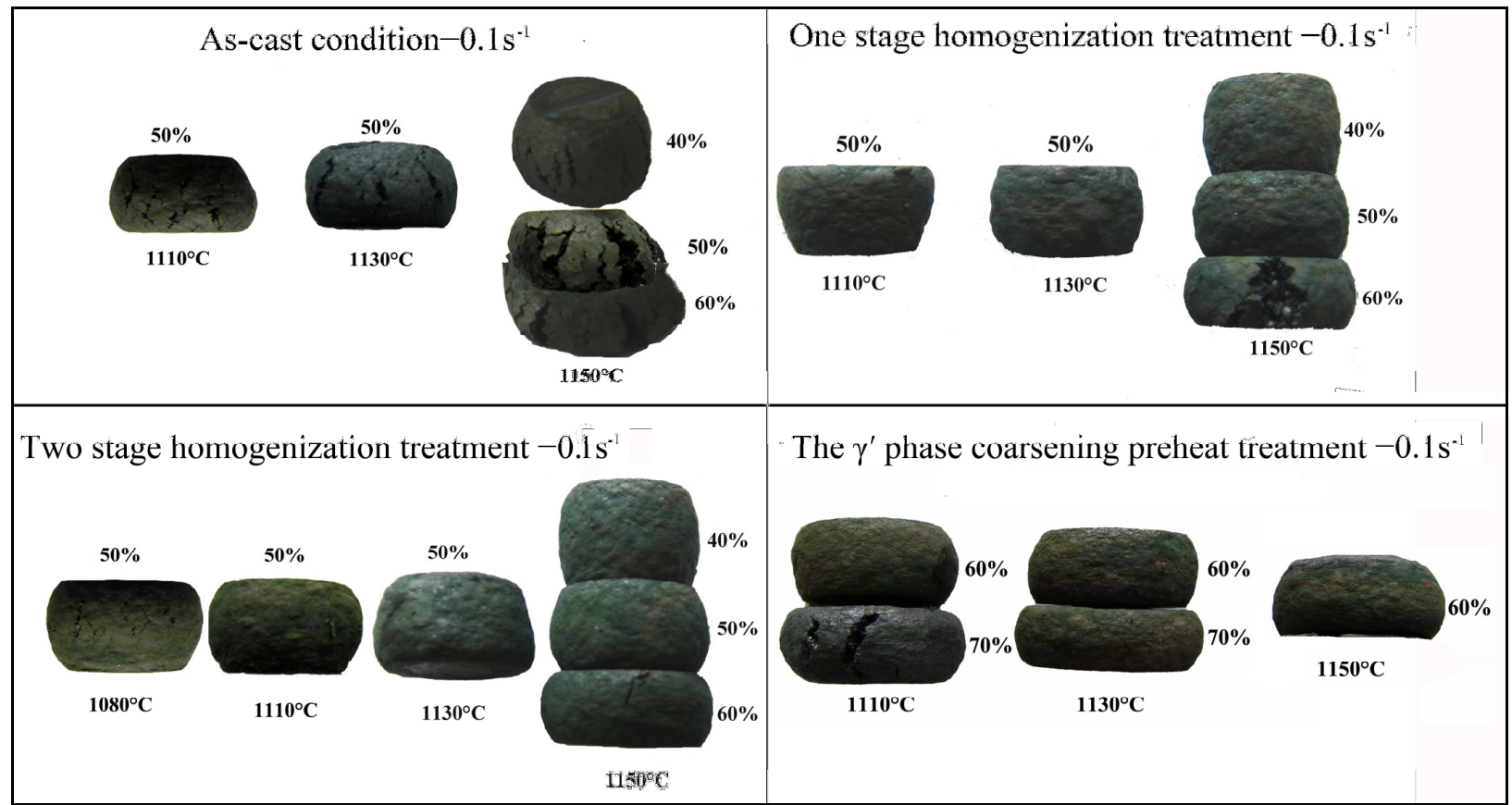

Figure 3 Isothermal compression samples after Gleeble tests at different conditions

\section{(2) Optimizing Forging Process}

Although several experimental pancakes have been produced using above processing method, cracks were observed when forging reduction is beyond $50 \%$ due to the remanent eutectic $\gamma+\gamma^{\prime}$. Moreover, incomplete recrystallization was also evident (Figure $4 \mathrm{~b}$ and e). Therefore, improvement of forgeability achieved by just optimizing the thermal treatment and the deformation parameters were considered to be insufficient. 

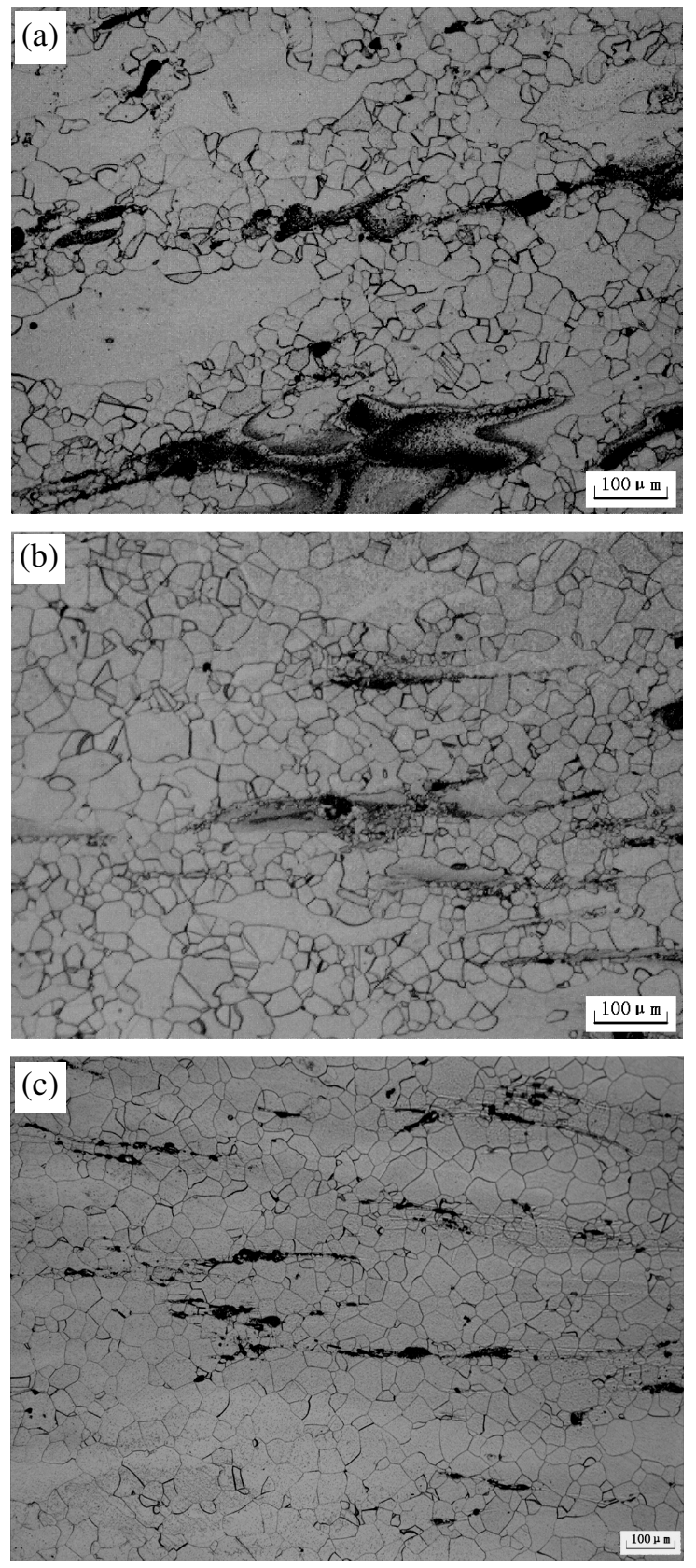
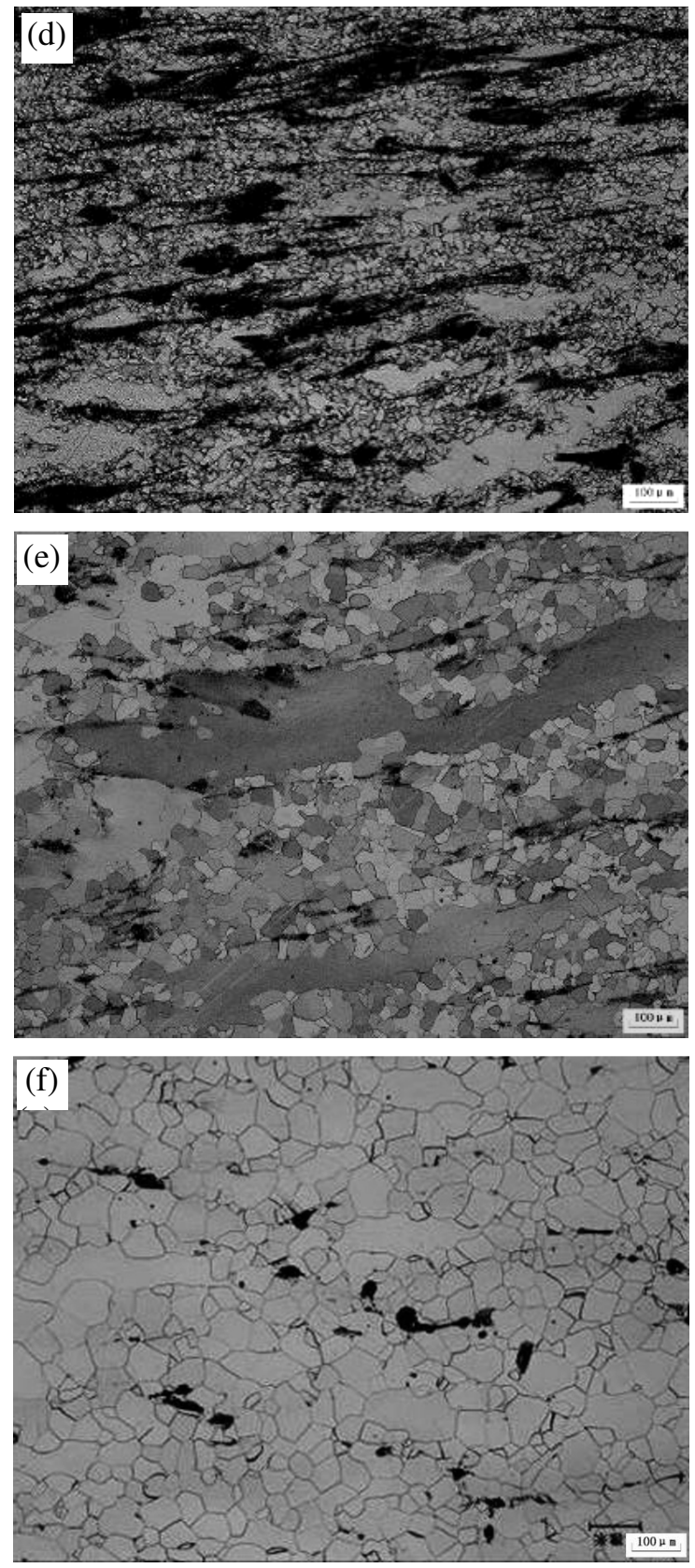

Figure 4 Recrystallization grain structure after deformation for GH720Li Samples deformed at $0.1 \mathrm{~s}^{-1}$ (a) $1110^{\circ} \mathrm{C}$ (b) $1130^{\circ} \mathrm{C}$ (c) $1150^{\circ} \mathrm{C}$ after one stage homogenization Samples deformed at $0.1 \mathrm{~s}^{-1}$ (d) $1110^{\circ} \mathrm{C}$ (e) $1130^{\circ} \mathrm{C}$ (f) $1150^{\circ} \mathrm{C}$ after two stage homogenization

Genereux and Fahrmanm's experimental results on an improvement in forgeability of highly alloyed superalloys indicate that an overage cycle before forging can not only improve the hot plasticity but also decrease the flow stress of the alloy [8,9]. Moreover, this overage cycle can promote recrystallization during hot deformation and fine grain billet can be achieved. Delta processed Inconel 718 developed a fine, uniform grain microstructure with a $\delta$ phase overage cycle before forging $[10,11]$. Therefore, a more sophisticated process was evaluated based on the results of the initial forging approach. The intention was to promote, through subsequent forging, 
dynamic recrystallization resulting in an uniform, fine grain structure.

Observing modest improvement in forgeability could be achieved through the thermal treatment, a method was developed to dramatically coarsen the $\gamma^{\prime}$ precipitates. The desired method to improve forgeability of GH720 Li is produced by taking advantage of the gradient in $\gamma^{\prime}$ solvus from grain center to grain boundary. This $\gamma^{\prime}$ solvus gradient is a result of composition gradient which exist in all castings. To coarsen the $\gamma^{\prime}$ phase, the sample is heated to a temperature slightly below the solution temperature of the intergranular eutectic $\gamma+\gamma^{\prime}$ to prevent grain growth. The key processing step is a slow controlled cool from this temperature through the $\gamma^{\prime}$ phase formation range. A combination of enhanced high temperature diffusion and decreasing solubility for $\gamma^{\prime}$ phase formers on cooling are believed to be responsible for the effectiveness of this $\gamma^{\prime}$ phase coarsening cycle. Figure 5 shows the coarse dendrite or fan-shaped $\gamma^{\prime}$ phase after the coarsening cycle.
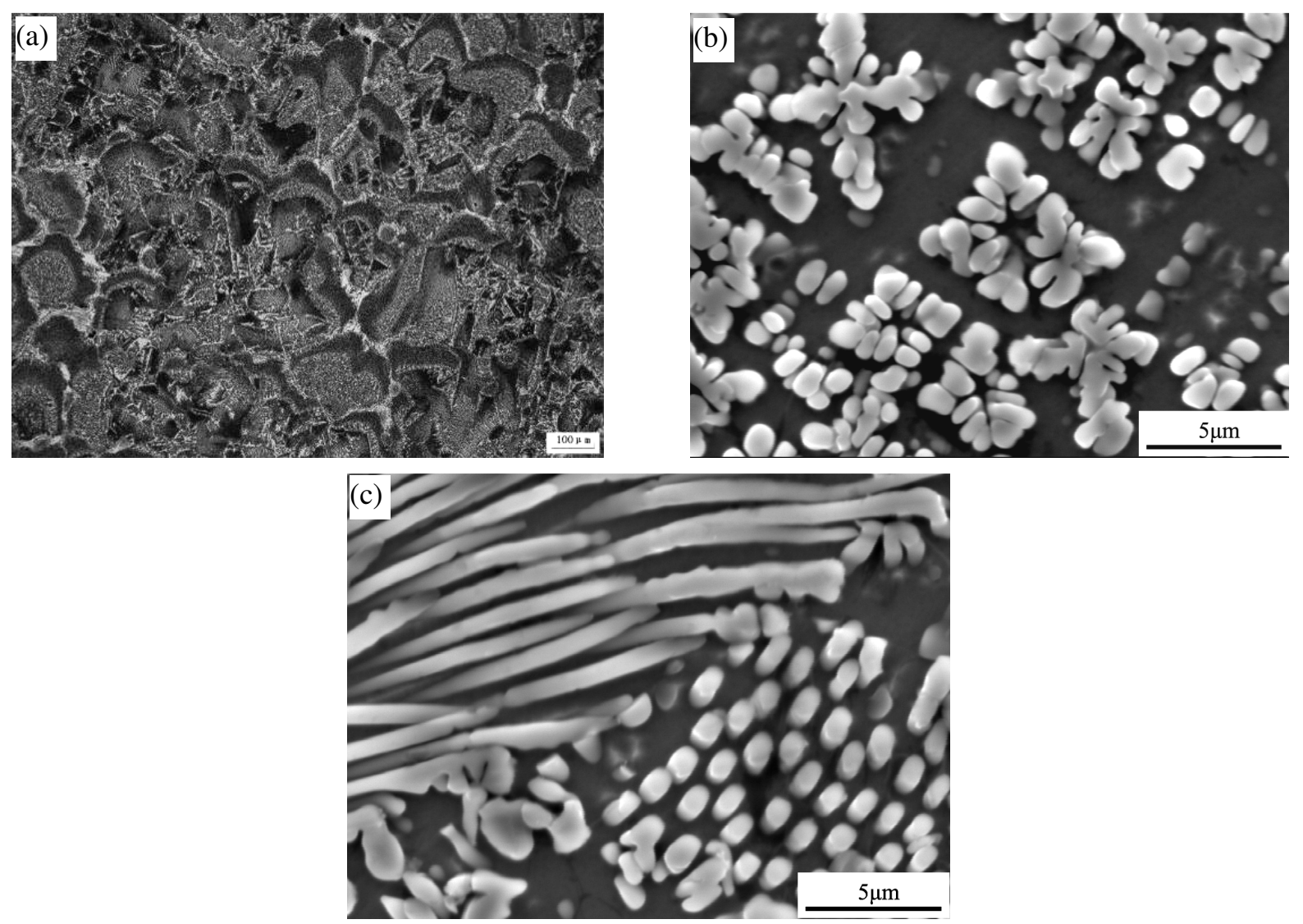

Figure.5 Microstructure of the specimen through the $\gamma^{\prime}$ phase coarsening cycle (a) $\gamma^{\prime}$ phase by OM (b)(c) dendrite or fan-shaped $\gamma^{\prime}$ phase by SEM

According to experimental results of the original forging approach, the specimens after the $\gamma^{\prime}$ phase coarsening cycle were deformed at different parameters. Figure 6 illustrate appearance and grain structure of the deformed samples after the coarsening cycle. This $\gamma^{\prime}$ phase coarsening cycle has provided a completely recrystallized structure at forging reductions as low as $50 \%$ in comparison with the original deformed samples after one or two stage thermal treatment (Figure $6 \mathrm{~b}$ and Figure $4 \mathrm{e}$ ) and even the maximum reduction at $1130^{\circ} \mathrm{C}$ can reach up to $70 \%$ without 
cracking. Figure 4, Figure 6 and Figure 7 illustrate that the volume fraction of recrystallization for one or two stage thermal treatment is remarkably lower than that of the $\gamma^{\prime}$ phase coarsening treatment deformed at $1130^{\circ} \mathrm{C}-0.1 \mathrm{~s}^{-1}-50 \%$. Furthermore, the flow stress obviously decreases in comparison with the original forge process (Figure 8).

Therefore, the $\gamma^{\prime}$ phase coarsening cycle before deformation not only improves hot plasticity but also achieves the $100 \%$ recrystallization grain structure for GH720Li.

Utilization this advanced cast technique and followed by hot die forging, a trial pancake with ASTM 7 fine grain structure has been achieved (Figure 9). After a solution and double aging heat treatment, mechanical properties and microstructural evaluations have been obtained on this trial pancake. Table $\Pi$ and Table $\amalg$ indicate that the trial pancake provided acceptable tensile and stress rupture properties, and they are well above the goal values.
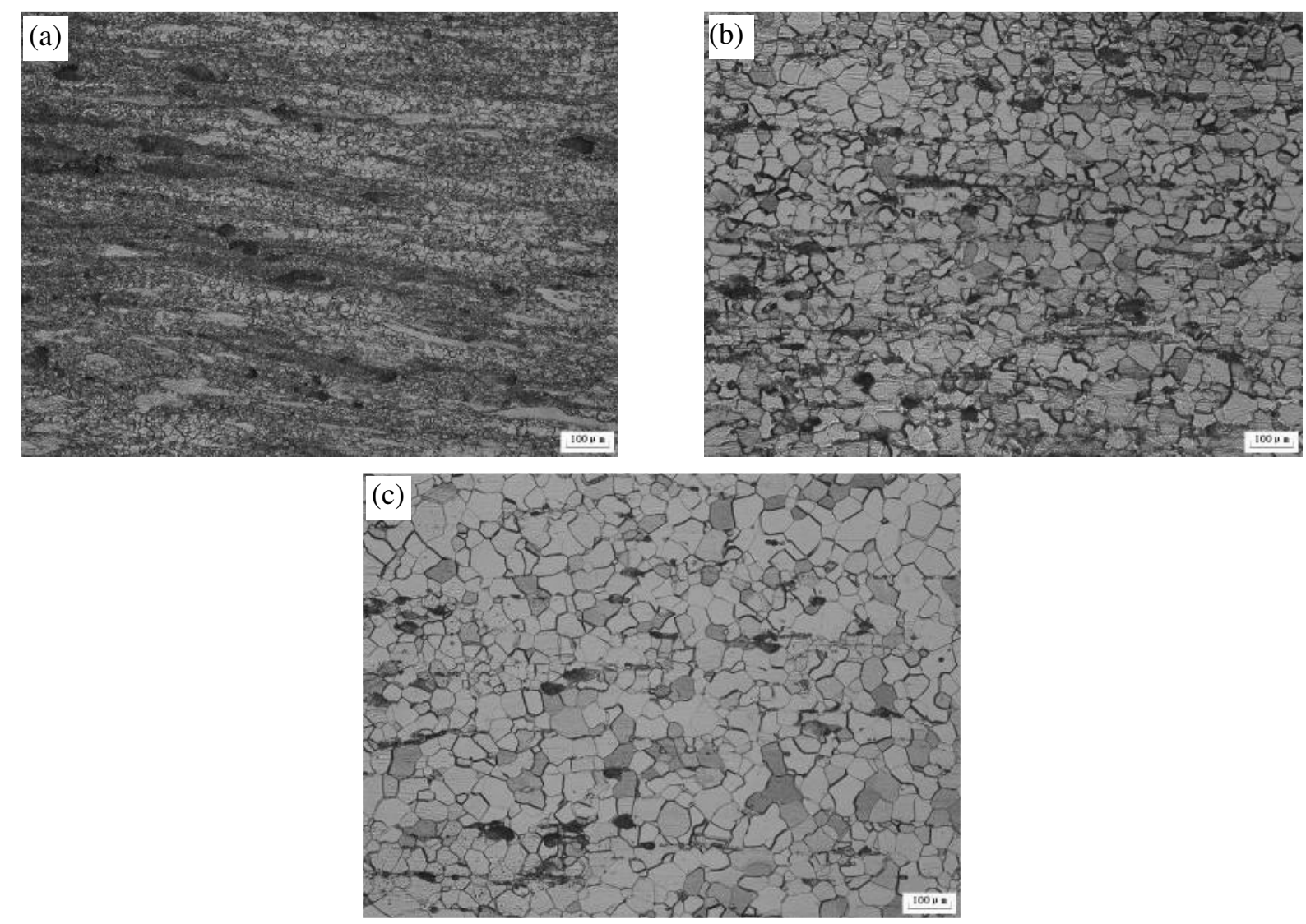

Figure 6 Samples deformed at $0.1 \mathrm{~s}^{-1}, 50 \%$ (a) $1110^{\circ} \mathrm{C}(\mathrm{b}) 1130^{\circ} \mathrm{C}$ (c) $1150^{\circ} \mathrm{C}$ after $\gamma^{\prime}$ phase coarsening cycle 


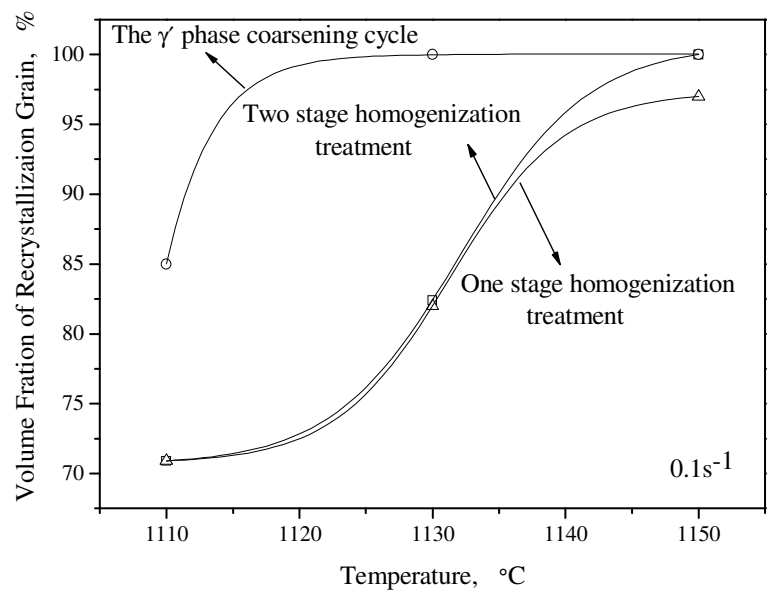

Figure 7 Comparison of volume fraction of recrystallization at different treatment before deformation at $50 \%$ reduction

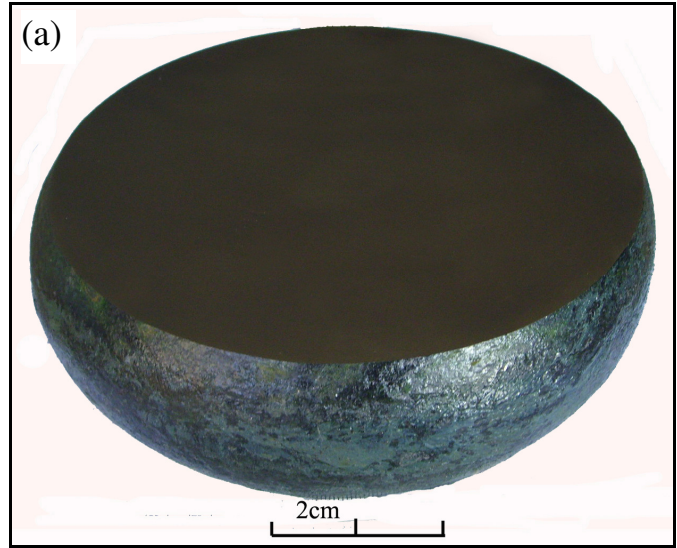

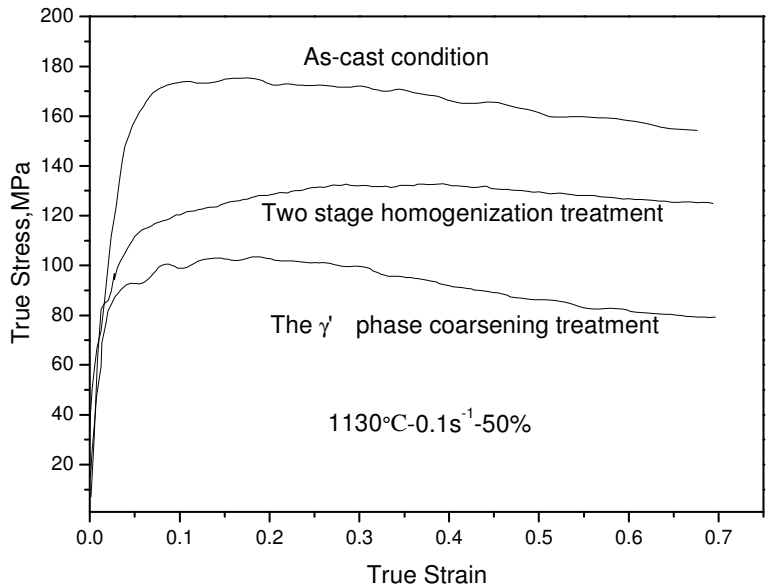

Figure 8 Flow stress of GH720Li after different treatment before deformation

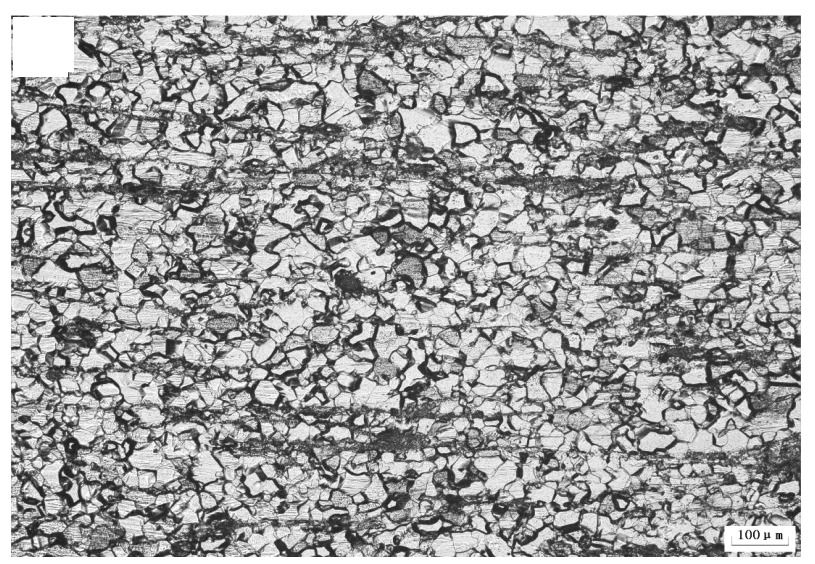

Figure 9 GH720Li trial pancake (a) and grain structure (b) after the optimization forging technique

Table II Tensile properties of the trial pancake

\begin{tabular}{|c|c|c|c|c|}
\hline Temperature, ${ }^{\circ} \mathrm{C}$ & $\begin{array}{c}\text { Ultimate Strength, } \\
\mathrm{MPa}\end{array}$ & $\begin{array}{c}\text { Yield Strength, } \\
\mathrm{MPa}\end{array}$ & Elongation, \% & $\begin{array}{c}\text { Reduction of } \\
\text { Area, } \%\end{array}$ \\
\hline 25 & 1525 & 1168 & 11.8 & 14.6 \\
\hline Goal at 25 & 1480 & 1050 & 7 & 9 \\
\hline 650 & 1392 & 1066 & 10.5 & 14.2 \\
\hline Goal at 650 & 1300 & 975 & 7 & 9 \\
\hline
\end{tabular}

Table Ш Stress rupture properties of the trial pancake

\begin{tabular}{|c|c|c|c|c|}
\hline Temperature, ${ }^{\circ} \mathrm{C}$ & Stress, MPa & Stress Rupture Life, $\mathrm{h}$ & Elongation, \% & $\begin{array}{c}\text { Reduction of } \\
\text { Area, } \%\end{array}$ \\
\hline 680 & 830 & 305.3 & 12.80 & 19.56 \\
\hline Goal at 650 & 830 & 25 & 4 & 10 \\
\hline
\end{tabular}




\section{Conclusions and Further Developments}

(1) This work described in this investigation clearly demonstrates the feasibility of converting $\mathrm{GH} 720 \mathrm{Li}$ alloy directly from fine grain ingot to forged pancake without powder process.

(2) Remarkable forgeability improvement of highly alloyed superalloy GH720Li can be achieved with a $\gamma^{\prime}$ phase coarsening pre-heat treatment process.

(3) Additional property testing is in process to validate that high property levels can be consistently achieved. This development will lead to form a cost effective production route for highly alloyed superalloy forgings.

\section{References}

1. D.J. Bryant and D.G. Mcintosh, "The Manufacture and Evaluation of a Large Turbine Disk in Cast and Wrought Alloy 720Li," Superalloys 1996, ed. R.D. Kissinger (Warrendale, PA: TMS, 1996), 713-722.

2. Y. Gu et al., "New Ni-Co-base Disk Superalloys with Higher Strength and Creep Resistance," Scripta Materialia, 55(2006), 815-818.

3. F.E. Sczerzenie et al., "Development of Udimet 720 for High Strength Disk Applications," Superalloys 1984, ed. S. Reichman (Warrendale, PA: TMS, 1984), 573-582.

4. D.U. Furrer, "The Evolution of Microstructure during Processing of Alloy-720" (Paper presented at the 11th International Symposium on Advanced Superalloys-Production and Application, Shanghai, China, 21 May 2007)

5 S.W. Kando, "Upcoming BR700 Core Tests to Focus on Endurance," Aviation Week \& Space Technology, (6) (1993), 53-54

6. J.M. Hyzak et al., "The Microstructural Response of As-HIP P/M U-720 to Thermomechanical Processing," Superalloys 1992, ed. S.D. Antolovich (Warrendale, PA: TMS, 1992), 93-101.

7. K.A. Green, J.A. Lemsky and R.M. Gasior, "Development of Isothermally Forged P/M Udimet 720 for Turbine Disk Applications," Superalloys 1996, ed. R.D. Kissinger (Warrendale, PA: TMS, 1996), 697-703.

8. P.D. Genereux and D.F. Paulonis, "Processing of High Superalloy Components," Superalloys 1988, ed. S.D. Antolovich (Warrendale, PA: TMS, 1992), 535-544.

9. M. Fahrmann and A. Suzuki, "Effect of Cooling Rate on Gleeble Hot Ductility of Udimet Alloy 720 billet,” Superalloys 2008, ed. E.A. Loria (Warrendale, PA: TMS, 2008), 311-316.

10. E.E. Brown, R.C. Boettner and D.L. Ruckle, "Minigrain ${ }^{\mathrm{TM}}$ Processing of Nickel-Base Alloys," Superalloys 1972, ed. E.A. Loria (Warrendale, PA: TMS, 1972), L1-L12. 
11. C. Ruiz, A. Obabueki and K. Gillespie, "Evaluation of the Microstructure and Mechanical Properties of Delta Processed Alloy 718," Superalloys 1992, ed. S.D. Antolovich (Warrendale, PA: TMS, 1992), 33-42. 